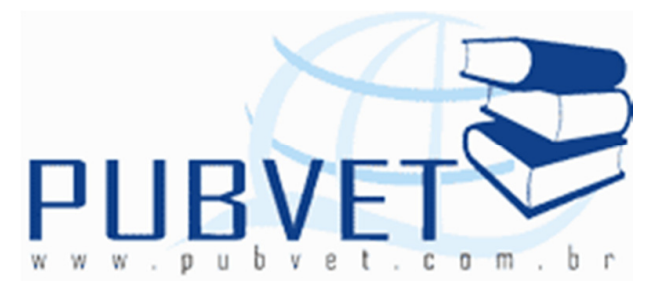

PUBVET, Publicações em Medicina Veterinária e Zootecnia.

\title{
Ultrassom terapêutico como tratamento na cicatrização de feridas em equinos
}

Júlia de Miranda Moraes ${ }^{1}$, Martha Oliveira Bravo ${ }^{2}$, Ana Lourdes Arrais de Alencar Mota ${ }^{2}$, Cinthia Beatriz Silva Dumont ${ }^{2}$, Lucas Cardoso Pereira ${ }^{2}$, Fábio Henrique Bezerra Ximenes ${ }^{2}$, Renata de Pino Albuquerque Maranhão ${ }^{3}$, Roberta Ferro de Godoy ${ }^{4}$

1 Universidade Federal de Goiás - Regional Jataí, Campus Jatobá, BR 364, Km 195, n3800, CEP 75801-615, Jataí-GO. E-mail: mmjulia.edu@gmail.com ${ }^{2}$ Hospital Veterinário de Grandes Animais-FAV/UnB, Galpão 4, Granja do Torto, Brasília - DF.

${ }^{3}$ Escola de Veterinária - UFMG, Av. Antônio Carlos 6627, campus Pampulha, Belo Horizonte - MG.

${ }^{4}$ University College of London, Institute of Orthopaedics and Musculoskeletal Science, London - UK.

\section{Resumo}

O Ultrassom terapêutico é uma modalidade de terapia alternativa que vem sendo amplamente utilizado pelos clínicos como auxílio ao tratamento durante o processo cicatricial após injúrias de diferentes origens, principalmente em feridas complicadas, nas quais o tempo de recuperação do animal costuma se estender. Neste estudo, foram apresentados 5 casos, três animais com feridas contaminadas e dois com feridas causadas pela habronemose cutânea, nas 
quais o uso do equipamento se mostrou eficiente, com diminuição do tempo de cicatrização e aceleração da epitelização das feridas.

Palavras-chave: Cicatrização, equinos, feridas complicadas, terapia alternativa, ultrassom terapêutico

\title{
Therapeutic ultrasound as a treatment in wound healing in equine
}

\begin{abstract}
The Ultrasound therapy is a form of alternative therapy that has been widely used by clinicians as an aid to treatment during the healing process after injury of different origins, especially in complicated wounds, in which the recovery time of the animal usually extend. In this study, were presented five cases, three animals with infected wounds and two with wounds caused by cutaneous habronemiasis, in which the use of the equipment is efficient, reducing the healing time and acceleration of epithelialization of wounds.
\end{abstract}

Keywords: alternative therapy, complicated wounds, healing, horses, therapeutic ultrasound

\section{Introdução}

O processo de cicatrização das feridas acontece fisiologicamente após uma injúria, independente da causa, sendo dividido didaticamente em três fases: fase inflamatória, na qual ocorre a migração de plaquetas e células inflamatórias como neutrófilos e macrófagos para o local da ferida; fase de proliferação, quando ocorre a formação do tecido de granulação, sendo os fibroblastos e as células endoteliais as principais envolvidas e, finalmente, fase de remodelação, na qual ocorre a deposição de colágeno de forma organizada, muito importante clinicamente (CAMPOS et al., 2007).

Existem diversos fatores que influenciam no processo cicatricial, como possíveis resíduos dentro da ferida, contaminação bacteriana e hipóxia tecidual (OLIVEIRA et al., 2012). No caso dos equinos, outro fator bastante relevante é 
MORAES, J.M. et al. Ultrassom terapêutico como tratamento na cicatrização de feridas em equinos. PUBVET, Londrina, V. 8, N. 16, Ed. 265, Art. 1760, Agosto, 2014.

a alta incidência de injúrias em membros locomotores, onde a disponibilidade de pele é escassa e há grande formação de tecido de granulação no local, o que requer maior cuidado terapêutico a fim de evitar a proliferação de um tecido de granulação exuberante (MORAES et al., 2009).Estes casos são desafios para os médicos veterinários que costumam eleger a cicatrização por segunda intenção para recuperação do tecido, seja pelas condições do mesmo ou pela falta de pele para recobrimento (PAGANELA et al., 2009)

Apesar do prognóstico favorável com relação à vida do animal, quando não tratadas corretamente, as feridas em equinos costumam evoluir de maneira indesejada, podendo acarretar prejuízos econômicos e perda do desempenho animal (PAGANELA et al., 2009).Diversos estudos têm sido realizados com o objetivo de acelerar o processo cicatricial e torná-lo mais organizado, melhorando o aspecto clínico final.Nesse sentido, o ultrassom terapêutico (UT)é um dos métodos alternativos mais utilizados como coadjuvantes na terapia convencional (OLSSON et al., 2008).

O UT é um tipo de energia não invasiva, utilizada como auxílio na cicatrização de feridas em diversas espécies, contudo, injúrias musculoesqueléticas são freqüentes nos equinos, sendo este método alternativo largamente utilizado nesses animais (MORAES et al., 2009).Ocorre estimulaçãoda produção de são células envolvidas no processo de cicatrização, como os fibroblastos, e também a produção de colágeno, resultando na diminuição do tempo de cicatrização e melhor força de tensão da ferida (MORAES et al, 2009).

É principalmente utilizado em feridas crônicas, porém, também pode ser utilizado para acelerar o processo inflamatório responsável pela chegada das células que auxiliam na cicatrização (OLSSON et al., 2008)). Além disso, o uso do UT estimula o fluxo sanguíneo, apresentando propriedades antiinflamatórias, analgésicas e diminuição do edema, promovendo diminuição da dor local (MORAES et al., 2009). 
MORAES, J.M. et al. Ultrassom terapêutico como tratamento na cicatrização de feridas em equinos. PUBVET, Londrina, V. 8, N. 16, Ed. 265, Art. 1760, Agosto, 2014.

\section{Relato dos casos}

Três éguas, adultas, sem raça definida, foram atendidas no Hospital Veterinário de Grandes Animais da FAV/UnB com histórico de neurectomia do nervo ulnar do membro torácico direito. Após aproximadamente três dias do procedimento cirúrgico, houve deiscência dos pontos das feridas, com sinais de infecção. O tratamento medicamentoso constituiu-se de fenilbutazona $(4,4 \mathrm{mg} / \mathrm{kg}$, IV, SID) por três dias e benzilpenicilina procaína $(20.000 \mathrm{UI} / \mathrm{kg}$, IM, SID) com três aplicações em dias alternados.

As feridas apresentavam exsudato, hemorragia, bordas eritematosas e edemaciadas e formação moderada de tecido de granulação. No animal A, a ferida apresentava medida de $15,1 \mathrm{~cm}^{2}$ (Figura A1), no animal $B$ de $23,32 \mathrm{~cm}^{2}$ (Figura B1) e no animal $C$ de $60,5 \mathrm{~cm}^{2}$ (Figura $C 1$ ). Foi instituído como tratamento o UST (Sonacel Dual - Bioset), aplicado pelo método direto, na presença de gel, sobre a pele epilada, com freqüência de $3 \mathrm{MHz}$ no modo pulsado (não-térmico), intensidade de $0,5 \mathrm{~W} / \mathrm{cm}^{2}$ e intensidade de pulso a $100 \mathrm{~Hz}$ a $50 \%$ por dez minutos ao redor das lesões.
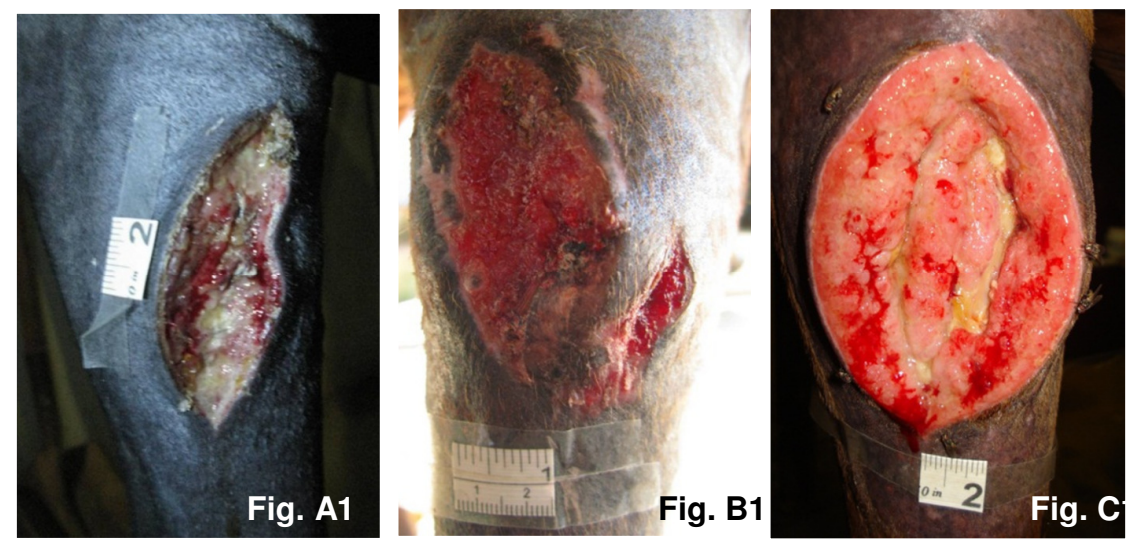

Figuras A1, B1 e C1: feridas apresentando medidas de $15,1 \mathrm{~cm}^{2}$, $23,32 \mathrm{~cm}^{2}$ de $60,5 \mathrm{~cm}^{2}$ nos animais A, B e C, respectivamente.

Realizava-se limpeza diária com solução de iodopovidona diluída, sendo que as feridas permaneceram abertas até a completa cicatrização com 
MORAES, J.M. et al. Ultrassom terapêutico como tratamento na cicatrização de feridas em equinos. PUBVET, Londrina, V. 8, N. 16, Ed. 265, Art. 1760, Agosto, 2014.

aplicação de repelente ao redor. No animal A, foram realizadas 15 sessões em 25 dias, no animal B foram 12 sessões em 16 dias e no do animal $C$ foram 23 sessões em 32 dias. As sessões eram realizadas diariamente, com exceção dos finais de semana.

No mesmo período, outros dois equinos, machos, adultos, foram atendidos no Hospital Veterinário de Grandes Animais da FAV/UnB com histórico de ferida extensa com formação moderada de tecido de granulação. No animal $A$ as feridas apresentavam-se na face lateral entre a quartela e o boleto do membro torácico esquerdo (MTE) e lateral próximo a coroa do casco do membro torácico direito (MTD) com medidas de $20,29 \mathrm{~cm}^{2}$ e $18,1 \mathrm{~cm}^{2}$ respectivamente. $O$ animal $B$ apresentava ferida na face caudal na porção ulnar do MTE com $88,44 \mathrm{~cm}^{2}$. Além do diagnóstico terapêutico, foi realizado exame histopatológico sendo confirmado o diagnóstico de habronemose. Como tratamento sistêmico foi instituído ivermectina $1 \%(0,2 \mathrm{mg} / \mathrm{kg} / \mathrm{IM} / \mathrm{SID})$, sendo 4 aplicações com intervalo de 7 dias. O animal A recebeu predinisolona via oral a $1 \mathrm{mg} / \mathrm{kg}$ durante 14 dias, seguida por $0,5 \mathrm{mg} / \mathrm{kg}$ por mais 14 dias. Como tratamento tópico foi manipulado pomada a base de carvão ativado, ivermectina $1 \%$, betametasona e dimetil sulfóxido (DMSO), sendo aplicada diariamente, juntamente com limpeza diária com iodopovidona diluída e bandagem compressiva. Foi instituído como tratamento coadjuvante o UST (Sonacel Dual - Bioset) aplicado pelo método direto, na presença de gel, sobre a pele epilada, no modo pulsado, freqüência de $3 \mathrm{MHZ}$ e com intensidade de $0,5 \mathrm{~W} / \mathrm{cm}^{2}$, ao redor das lesões, totalizando 15 minutos de tratamento. As aplicações foram realizadas duas vezes por semana no animal A perfazendo oito sessões em 30 dias, e em dias alternados no animal B, perfazendo 52 sessões em 90 dias.

\section{Resultados e discussão}

Após 13 dias de tratamento das três éguas, a ferida do animal $A$ teve uma redução de $70 \%$ do tamanho inicial, ficando com $4,5 \mathrm{~cm}^{2}$ (Figura A2), a 
MORAES, J.M. et al. Ultrassom terapêutico como tratamento na cicatrização de feridas em equinos. PUBVET, Londrina, V. 8, N. 16, Ed. 265, Art. 1760, Agosto, 2014.

do animal B teve redução de 52\%, ficando com 11,2 $\mathrm{cm}^{2}$ (Figura B2) após cinco dias de tratamento e no animal $C$ houve uma redução de $82 \%$, ficando a ferida com $11 \mathrm{~cm}^{2}$ (Figura C2) após 22 dias de tratamento. Ao final da terapia com UST as feridas mediam $0,87 \mathrm{~cm}^{2}, 6,5 \mathrm{~cm}^{2}$ e $3,1 \mathrm{~cm}^{2}$ (Figuras A3, B3 e C3), ou seja, reduziram $94,2 \%, 72,1 \%$ e $94.8 \%$ de seus tamanhos iniciais, respectivamente.
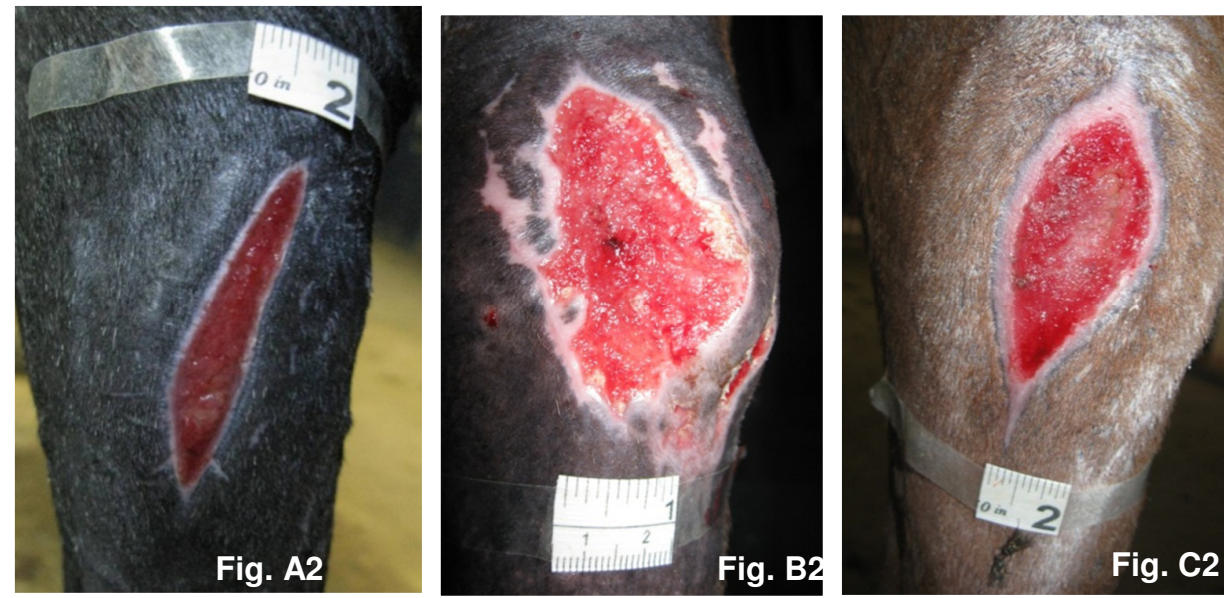

Figuras A2, B2 e C3: feridas medindo $4,5 \mathrm{~cm}^{2}, 11,2 \mathrm{~cm}^{2}, 11 \mathrm{~cm}^{2}$, nos animais A, B e C após 12, 5 e 22 dias de tratamento, respectivamente.
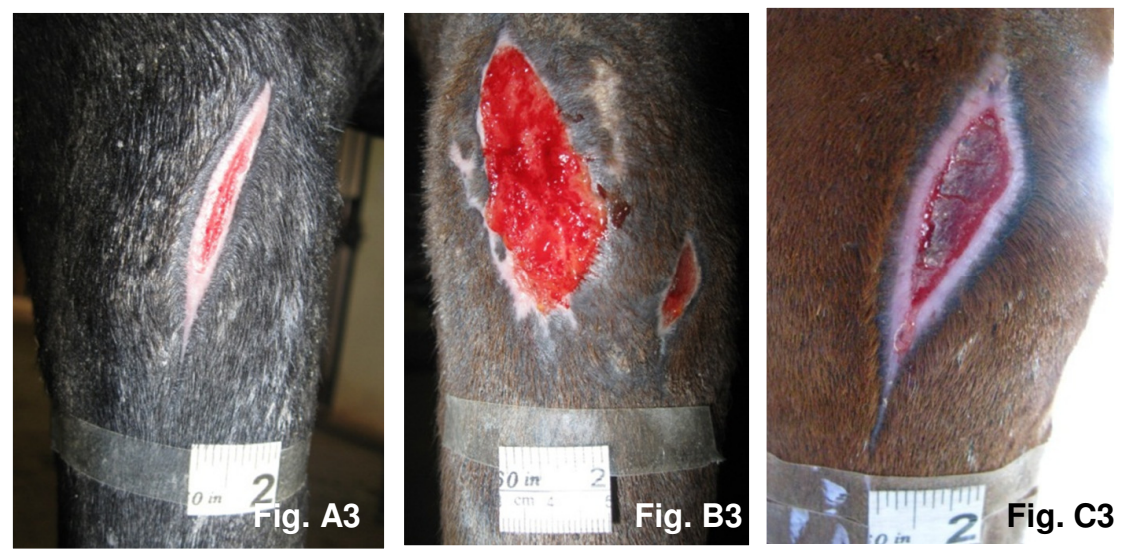

Figuras A3, B3 e C3: Final do tratamento, feridas medindo respectivamente $0,87 \mathrm{~cm}^{2}, 6,5 \mathrm{~cm}^{2}$ e $3,1 \mathrm{~cm}^{2}$. 
MORAES, J.M. et al. Ultrassom terapêutico como tratamento na cicatrização de feridas em equinos. PUBVET, Londrina, V. 8, N. 16, Ed. 265, Art. 1760, Agosto, 2014.

Nesta etapa foram finalizadas as aplicações, pois as feridas se encontravam em estágio final de cicatrização, com boa epitelização e retração de bordas e ausência de tecido de granulação. Com o uso do UST, ocorreu uma rápida modulação da resposta inflamatória e do tecido de granulação local, promovendo uma excelente retração das bordas com boa epitelização tecidual.

Isso de deve à uma maior estimulação da proliferação fibroblástica e consequente formação de colágeno, proporcionando uma maior força de tensão para a ferida cicatrizada. Pode-se inferir, portanto, que o tratamento com uso do UT se mostra efetivo no caso de feridas de difícil cicatrização, como as feridas com contaminação bacteriana.

No caso dos dois equinos com habronemose cutânea, após trinta dias de tratamento, as feridas do animal A reduziram aproximadamente $86 \%$ do seu tamanho inicial, ficando com $2,8 \mathrm{~cm}^{2}$ na face lateral e $3,1 \mathrm{~cm}^{2}$ na face medial. No animal B, houve redução de $62 \%$ da ferida, ficando com $33,8 \mathrm{~cm}^{2}$. Nesta fase, as feridas dos dois animais apresentavam boa epitelização e retração de bordas e ausência de tecido de granulação. Neste período o animal A recebeu alta do tratamento. No início da terapia com UST, o animal A já se apresentava em estágio inativo da habronemose, ao contrário do animal B que estava na fase aguda da doença, o que provavelmente aumentou o tempo necessário para cicatrização da ferida. Aos 90 dias de tratamento a ferida do animal B reduziu $98,5 \%$ ficando com $1,31 \mathrm{~cm}^{2}$ e completa cicatrização tecidual.

\section{Conclusão}

Nestes relatos pôde-se comprovar a eficácia terapêutica do UST, como um método não invasivo de tratamento tanto para feridas tanto sépticas, como na aceleração da cicatrização de habronemose cutânea de eqüinos, sendo o método pulsátil a modalidade de eleição para processos agudos, demonstrando maior agilidade e qualidade na cicatrização tecidual. Além disso, o tratamento com UST foi essencial para a modulação da resposta inflamatória, do tecido de granulação e da epitelização tecidual. Ao final do tratamento, observou-se 
MORAES, J.M. et al. Ultrassom terapêutico como tratamento na cicatrização de feridas em equinos. PUBVET, Londrina, V. 8, N. 16, Ed. 265, Art. 1760, Agosto, 2014.

completa cicatrização das feridas, com boa epitelização e tensão na área cicatricial.

\section{Referências bibliográficas}

Campos et al. Cicatrização de feridas. ABCD ArqBrasCirDig 2007;20(1):51-8.

Oliveira et al. Cicatrização de feridas: fases $e$ fatores de influência.ActaVeterinariaBrasilica, v.6, n.4, p.267-271, 2012.

Moraes JM et al. Therapeutic ultrasound as treatment in equine wounds.In: $11^{\text {th }}$ Congress of the world equine veterinary association, Guarujá, 2009. Anais....

Olssonet al. Ultra-som terapêutico na cicatrização tecidual. Ciência Rural, Santa Maria, v.38, n.4, p.1199-1207, jul, 2008.

Paganelaet al. Abordagem clínica de feridas cutâneas em equinos. RPCV (2009) 104 (569-572) 13-18. 